\title{
XXXV. The theory of "Moving Coil" and other kinds of ballistic galvanometers
}

\author{
Prof. Harold A. Wilson M.A. D.Sc. M.Sc. F.R.S.
}

To cite this article: Prof. Harold A. Wilson M.A. D.Sc. M.Sc. F.R.S. (1906) XXXV. The theory of "Moving Coil" and other kinds of ballistic galvanometers, Philosophical Magazine Series 6, 12:69, 269-272, DOI: 10.1080/14786440609463542

To link to this article: http://dx.doi.org/10.1080/14786440609463542

册 Published online: 16 Apr 2009.

Submit your article to this journal $[\pi$

Џll Article views: 3

Q View related articles $\asymp$ 
XXXV. The Theory of "Moving Coil" and other kinds of" Ballistic Galvanometers. By Prof. Harold A. Wilson, M.A., D.Sc., M.Sc., F.R.S.*

A FORMULA which is usually given for ballistic galvanometers is

$$
Q=\frac{\mathrm{HT}}{\mathrm{G} \pi} \sin \frac{\theta}{2}
$$

where $Q=$ quantity of electricity passed through galvanometer.

$\mathrm{H}=$ magnetic field controlling the galvanometer-needle.

$G=$ magnetic field at needle, supposed perpendicular to $\mathrm{H}$, due to unit current in the coil.

$\mathrm{T}^{\mathrm{T}}=$ - time of a complete oscillation of the needle.

$\theta=$ angle of swing of the needle from rest corrected for damping.

If $\phi$ is the steady angular deflexion due to a current $i$, then $i=\frac{\mathrm{H}}{\mathrm{G}} \tan \phi ;$ so that

$$
\mathrm{Q}=\frac{\mathrm{T} i \sin \theta / 2}{\pi \tan \phi}
$$

The above formula are of course, strictly speaking, only applicable to ballistic galvanometers consisting of a coil of wire having a single small magnet freely suspended at the centre of the coil, and arranged so that at its equilibrium position the axis of the magnet is in the plane of the coil.

In the following paper the proper formulæ for ballistic galvanometers of several types in general use are obtained, and it is found that in several cases they differ appreciably from the above.

In Prof. Fleming's 'Handbook for the Electrical Iaboratory and 'Testing Room,' vol. ii., the formula for a moving-coil galvanometer is worked out; but owing to an approximation used in the calculation it is not obtained exactly, and it is afterwards given as applying to both moving-coil and movingneedle galvanometers.

The first type of galvanometer that will be considered is the moving-coil type with a rectangular coil, cylindrical iron core and cylindrical pole-pieces symmetrically arranged. In galvanometers of this type the magnetic field is approximately radial, so that the couple on the coil due to a steady current is proportional to the current and independent of the deflexion. The controlling couple is due to the torsion of the wire by which the coil is suspended, so that the work required to turn

* Communicated by the Physical Society : read May 25, 1906. 
the coil through an angle $\theta$ from its zero position is $\frac{\alpha \theta^{3}}{2}$, where $\alpha$ is the couple exerted by the wire when the coil is turned through the unit angle. Let $\mathrm{C} i$ denote the couple due to a current $i$, then we have $\mathrm{C} i=\alpha \phi$. When a current $i$ is passed through the galvanometer for a short time $d t$, we have

$$
\mathrm{C} i d t=\mathrm{C} d \mathrm{Q}=\mathrm{K} d \omega
$$

where $\mathbf{E}$ is the moment of inertia of the coil and $\omega$ its angular velocity. Hence

We have also

$$
Q=\int i d t=\int \frac{K d \omega}{(j}=\frac{K \omega}{\mathrm{C}} .
$$

$$
\mathrm{T}=2 \pi \sqrt{\alpha} \frac{\mathrm{K}}{a} \text { and } \frac{\alpha \theta^{2}}{2}=\frac{1}{2} \mathrm{~K} \omega^{2}
$$

hence

$$
\mathrm{l}=2 \pi \sqrt{\frac{\theta^{2}}{\omega^{2}}=\frac{2 \pi \theta}{\omega} .}
$$

Thus:

$$
\mathrm{Q}=\frac{\mathrm{K} \omega}{\mathrm{C}}=\frac{\alpha \theta^{2}}{\mathrm{C \omega} \omega}=\frac{\mathrm{T} \alpha \theta}{2 \pi \mathrm{U}} .
$$

But $\stackrel{c}{C}=\stackrel{?}{\phi}$; so that finsti:y

$$
Q_{2}=\frac{T i \theta}{2 \pi \phi} \text { exactly. }
$$

Since the couple on the coil due to the current is undependent of $\theta$, it is not necessary with this type of instrument that the time during which the transient current passes should be very small compared with $\mathrm{T}$.

Another type of moving-coli instrument in common ase has a narrow coil suspended between the poles of a magnes and no iron core. In this case, the couple on the coil due to a current $i$ will be nearly $\mathrm{C} i \cos \phi$, so that $\mathrm{C} i \cos \phi=\alpha \phi$ or $\frac{\alpha}{\mathrm{C}}=\frac{i \cos \phi}{\phi}$; hence the exact formulæ for this type of instrument are

$$
Q=\frac{\mathrm{T} \alpha \theta}{2 \pi \mathrm{C}}=\frac{\mathrm{T} i \theta \cos \phi}{2 \pi \phi} .
$$

In these formulæ it is assumed that the plane of the coil at its zero position is parallel to the magnetic field.

It appears, therefore, that the first type of moving-coil ballistic galvanometer considered is superior to the second in respect of the simplicity of the exact formulæ to be used with it, and the absence of error when the transient current lasts an appreciable time. 
Moving-needle instruments will now be considered. The formulie

$$
\mathrm{Q}=\frac{\mathrm{HT} \sin \theta / \dot{z}}{\mathrm{G} \pi} \text { and } \mathrm{Q}=\frac{\mathrm{T} i \sin \theta / 2}{\pi \phi}
$$

apply to what may be called a tangent ballistic galvanometer. The time of the transient current must of course be sinall compared with 'T, and its greatest value must not be sufficient to appreciably change the magnetism of the needle.

In many ballistic galvanometers an astatic system of needles is used. First, suppose the system is exactly astatic and that the torsion of a wire or quartz fibre supplies the controlling couple. In this case, $\mathrm{C} i \cos \phi=x \phi$ and $\mathrm{K} \omega^{2}=u \theta^{2}$, so that the formulie are

$$
\mathrm{Q}=\frac{\mathrm{T} \alpha \theta}{2 \pi \mathrm{C}}=\frac{\mathrm{T} i \theta \cos \phi}{2 \pi \phi},
$$

as with the second type of moving-coil instrument. Also $\mathrm{C}=\mathrm{M}\left(\mathrm{G}_{1}+\mathrm{G}_{2}\right)$, where $\mathrm{M}$ is the moment of each needle and $G_{1}$ and $G_{2}$ the fields due to unit current at the two needles respectively.

One other case will be considered, viz. when the needle system is more or less astatic and is controlled by magnetic fields at each needle. Let the horizontal component of the controlling field at one needle be $\mathrm{H}_{1}$ making an angle $\alpha_{1}$ with the plane of this needle, and let $\mathrm{M}_{1}$ be the moment of this needle. Let $\mathrm{M}_{2}, \mathrm{H}_{2}$, and $\alpha_{2}$ be the corresponding quantities at the other needle. Then in the equilibrium position,

$$
\mathrm{O}=\mathrm{M}_{1} \mathrm{H}_{1} \sin \alpha_{1}+\mathrm{M}_{2} \mathrm{H}_{2} \sin \alpha_{2} \text {. }
$$

The controlling couple when the needle is deflected through an angle $\phi$ is

$$
\begin{aligned}
\mathrm{M}_{1} \mathrm{H}_{1} \sin \left(\phi+\alpha_{1}\right)+ & \mathrm{M}_{2} \mathrm{H}_{2} \sin \left(\phi+\alpha_{2}\right) \\
& =\left\{\mathrm{M}_{1} \mathrm{H}_{1} \cos \alpha_{1}+\mathrm{M}_{2} \mathrm{H}_{2} \cos \alpha_{2}\right\} \times \sin \phi ;
\end{aligned}
$$

and if $\phi$ is the deflexion due to a current $i$, then $i \mathrm{M}_{1} \mathrm{G}_{1} \cos \phi+i \mathrm{M}_{2} \mathrm{G}_{2} \cos \phi=\sin \phi\left\{\mathrm{M}_{1} \mathrm{H}_{1} \cos \alpha_{1}+\mathrm{M}_{2} \mathrm{H}_{2} \cos \alpha_{2}\right\}$. Hence

$$
i=\frac{\mathrm{M}_{1} \mathrm{H}_{1} \cos \alpha_{1}+\mathrm{M}_{2} \mathrm{H}_{2} \cos s_{2}}{\mathrm{M}_{1} \mathrm{G}_{1}+\mathrm{M}_{2} \mathrm{G}_{2}} \tan \phi .
$$

It can now be easily seen that the formulæ for a ballistic galvanometer of this type are

$$
\mathrm{Q}=\frac{\mathrm{T}\left(\mathrm{M}_{1} \mathrm{H}_{1} \cos \alpha_{1}+\mathrm{M}_{2} \mathrm{H}_{2} \cos \alpha_{2}\right) \sin \theta / 2}{\pi\left(\mathrm{M}_{1}\left(\mathrm{G}_{1}+\mathrm{M}_{2} \mathrm{G}_{2}^{-}\right)\right.} \text {and } \mathrm{Q}=\frac{\mathrm{T} i \sin \theta / 2}{\pi \tan \phi} \text {. }
$$

So far the correction of the observed deflexion $\theta$ for damping bas been neglected. The method usually described depends on the "logarithmic decrement," and is cumbrous, and moreover inexact unless the damping is very small. The 
272 Moving Coil and other kinds of Ballistic Galvanometers.

following method has the great advantages of simplicity and exactness ; it is not new: the writer learned it abont ten years ago from Prof. W. Stroud.

Let $\theta_{1}, \theta_{2}, \theta_{3}$, \&c. be the successive swings of the galvanometer-needle. Then

$$
\frac{\theta_{1}}{\theta_{2}}=\frac{\theta_{2}}{\theta_{3}}=\frac{\theta_{3}}{\theta_{4}}=\& \mathrm{c} .=f \text { say. }
$$

To find $f$ observe, say, $\theta_{1}$ and $\theta_{3}$ or $\theta_{1}$ and $\theta_{5}$.

Then

$$
f^{2}=\frac{\theta_{1}}{\theta_{3}} \text { or } f^{4}=\frac{\theta_{1}}{\theta_{5}} \text {. }
$$

Also the corrected value of the first swing is

$$
\theta_{1} \sqrt{\vec{f}}=\theta_{1}\left(\frac{\theta_{9}}{\theta_{3}}\right)_{-}^{\frac{1}{2}}=\theta_{1}\left(\frac{\theta_{1}}{\theta_{5}}\right)^{\frac{1}{2}} \text {. }
$$

In most cases the angular deflexions may be taken as proportional to the deflexions on the scale. Let these be $\delta_{1}$, $\delta_{2}, \delta_{3}, \& \mathrm{c}$. Then the corrected value of the first swing is

$$
\delta_{1}\left(\frac{\delta_{1}}{\delta_{3}}\right)^{\frac{1}{2}} \text { or } \delta_{1}\left(\frac{\delta_{1}}{\delta_{5}}\right)^{\frac{1}{x}}
$$

If the damping is small the corrected value is very nearly $\delta_{1}+{ }_{4}-\left(\delta_{1}-\delta_{3}\right)$, and this formula is sufficiently exact for most purposes in practice.

The following table contains a summary of the results obtitined :--

Type of Galvanometer.

Formula.

(1) Tangent Galvanometer with small needle at centre of coil.

$$
\mathrm{Q}=\frac{\mathrm{HT}}{\mathrm{G} \pi} \sin \frac{\theta}{2}, \quad \mathrm{Q}=\frac{\mathrm{T} i \sin \theta / 2}{\pi \tan \phi} .
$$

(2) Astatic Galvanometer with purely torsional control.

$$
\mathrm{Q}=\frac{\mathrm{T} \alpha \theta}{2 \pi \mathrm{M}\left(\mathrm{G}_{1}+\overline{\mathrm{G}}_{2}\right)}, \quad \mathrm{Q}=\stackrel{\mathrm{T} i \theta \cos \phi}{2 \pi \phi} .
$$

(3) Astatic Galvanometer with purely magnetic control.

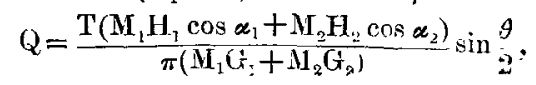

$$
Q=\frac{T i \sin \theta / 2}{\pi \tan \phi} \text {. }
$$

(4) Moving-coil C'alranometerwith iron cort and radial magnetic field.

$$
Q=\frac{T \alpha \theta}{2 \pi \mathrm{C}}, \quad \mathrm{Q}=\frac{\mathrm{T} i \theta}{2 \pi \phi},
$$

(5) Moving-coil Galranometer with narrow coil and no core.

$$
\mathrm{Q}=\frac{\mathrm{T} \kappa \theta}{2 \pi \mathrm{C}}, \quad \mathrm{Q}=\frac{\mathrm{T} i \theta \cos \phi}{2 \pi \phi},
$$

It will be seen that type (4) is superior to all the others as regards the simplicity of the exact formula to be used with it. It is also superior in most other respects. Galvanometers are often met with in practice which strictly speaking do not belong to any of the simple types considered in this paper. In such cases the exact formulæ are more complicated, and the best plan to adopt is to determine experimentally the relation between $\theta$ and $Q$. 